\title{
Developments
}

\section{Distribution as the Organizing Principle of Environmental Regulation}

\author{
By Suryapratim Roy*
}

\begin{abstract}
This Article argues that distributional concerns constitute the heart of environmental regulation; they are not restricted to pre-policy values or post-policy effects that need to dealt with. On the contrary, they characterize the selection of environmental policies, and their properties. Different interests, preferences, and values with respect to a policy instrument can be made commensurable using the language of distribution. The centrality of distribution as an organizing principle may be elusive on account of it being too vaguely construed or too narrowly defined. This necessitates the articulation of a typology of distributional concerns. To this end, it is suggested that the distribution of benefits and burdens, distribution of responsibility, distribution of membership and distribution of capabilities could be useful categories to develop and assess environmental regulation. This framework is then applied to an unsuspecting candidate, the European Union Emissions Trading Scheme (EU ETS).
\end{abstract}

\footnotetext{
* Assistant Professor in Regulatory Law, School of Law, Trinity College Dublin. Email: surya.roy@tcd.ie. I would like to thank the anonymous reviewers of the journal for their helpful review, and the editors for their careful edits. I would also like to thank Fabrizio Fracchia, Josephine van Zeben, Kenneth R. Richards, Oscar Couwenberg and Edwin Woerdman for helpful discussions on the subject.
} 


\section{A. Introduction}

If all individuals and collectives-families, communities, firms, governments, nongovernmental organizations-were perfectly equal and had perfect mobility; if they were free to move across places and jobs without any difficulty, then there would be no need to worry ourselves with distribution. Should equality and mobility be contingent on where one is situated financially, historically, spatially, then it would be difficult to relocate-or even conceive of relocating-somewhere where the air is purer, or the health effects of waterborne diseases lesser. Climate change adds an interesting dimension to such contingencyif all places in the world are equally problematic in future, then irrespective of the ability to negotiate social spaces, one might have to move outside the world, or back in time. The inevitability of contingency in a finite world points to the centrality of distribution in environmental decision-making.

The abovementioned view is admittedly in contrast with the notion that distributional concerns exist outside the boundaries of a particular environmental policy. Per this view, pre-policy distributional concerns are not the concern of rational decision-making, and postpolicy distributional impacts may be corrected by way of extra-policy mechanisms. If we were to adopt the view that pre-policy distributional concerns are not the concern of rational decision-making, then the scope for review of such policies cannot be on distributional grounds. Rather, the substance of review is a body of technical considerations, which limits the scope for review of environmental policies. With regard to post-policy impact, what is sought to be corrected is usually the redistribution of wealth as a consequence of policy-making. In terms of law, the concern here is more about the separation of powers - and in federal or quasi-federal systems, the division of powers. The thinking behind this is that distributional choices are political choices that are beyond the remit of specialized executive agencies, and what needs to be corrected are distributional changes brought about by policies. If there is a role for review, then that would be the possibility of judicial intervention pursuant to claims based on constitutional rights, ${ }^{1}$ rights under civil law, and common law remedies. ${ }^{2}$ Rights-based cases and common law claims in

\footnotetext{
1 There is a substantial body of scholarship on the centrality of civil and constitutional rights to American environmental law. For a review of the initial developments, see Richard Lazarus, Pursuing "Environmental Justice": The Distributional Effects of Environmental Protection, 87 NW. L. R. 787 (1993).

${ }^{2}$ In common law jurisdictions, tort law has played a role in highlighting distributional concerns in public law. See Benjamin Pontin, The Common Law Clean Up of the "Workshop of the World": More Realism About Nuisance Law's Historic Environmental Achievements, $40 \mathrm{~J}$. L. Soc'Y 173 (2013). In civil law countries, civil remedies have been mooted based on duty of care jurisprudence. In the recent Urgenda judgment, a group of Dutch citizens successfully obtained a Reduction Order from The Hague District Court requiring more stringent climate regulation. Their claim was based primarily on the duty of care jurisprudence developed under Dutch civil law. Stichting Urgenda v. Gov't of the Netherlands (Ministry of Infrastructure \& Env't), ECLI:NL:RBDHA:2015:7145, Rechtbank Den Haag (Hague District Court).
} 
several jurisdictions have played a role in identifying pre-policy and correcting post-policy adverse distributional impacts of environmental policy.

Other than the contribution of rights-based claims that have introduced a language of nondiscrimination, as will be discussed in more detail below, the inevitability of distributional choices in reasoning about policies has been highlighted by realist legal thought since the 1960s. This is true for both dominant branches of realist legal thought-Law \& Economics (L\&E) as well as Critical Legal Studies (CLS). Environmental law scholars who equate L\&E with the economic analysis of law are indifferent to distributional questions in analyses of policy choices, as it hampers the sanitized flow of economic language and measurements. Starting with Guido Calabresi, however, distribution has been at the heart of reasoning about policy choices. Calabresi pointed out that any regulatory intervention takes place in a world where there are distributional differences. ${ }^{3}$ Thus, unlike economic analysis that assumes rational individuals who can compete freely in social spaces, there is no assumption about individuals and collectives disposed towards and capable of profit maximization. ${ }^{4}$ This does not take away from the L\&E orientation that a policy decision inevitably involves a negotiation of values and interests, entailing some winners and losers. ${ }^{5} \mathrm{CLS}$ - derived largely from critical race theory and gender studies - was agnostic about the sanctity of both markets as well as the role of the state in organizing social relations. ${ }^{6}$ This line of scholarship pointed to the complicity between social norms and legal choices; this is instructive for considering particular policy instruments as they are situated within a larger socio-legal complex.

This Article proceeds as follows: First, I provide an overview of different approaches to thinking about the idea of distribution. Second, I examine the role of distribution in policymaking. Third, I apply the discussion to a particular policy, namely the European Union Emissions Trading Scheme (EU ETS).

\footnotetext{
${ }^{3}$ Calabresi and Melamed argue that regulatory choices about efficiency are essentially choices about distribution: "what is a Pareto optimal, or economically efficient, solution varies with the starting distribution of wealth. Pareto optimality is optimal given a distribution of wealth, but different distributions of wealth imply their own Pareto optimal allocation of resources." Guido Calabresi \& Douglas Melamed, Property Rules, Liability Rules and Inalienability: One View of the Cathedral, 85 HARV. L. REV. 1089, 1096 (1970).

${ }^{4}$ Other than differences in the distribution of wealth, Calabresi characterizes transaction costs as distributional impediments: ". . . the cost of information to each party, the absence of psychological or other impediments to acting on the basis of available information, the administrative costs of shifting losses, and the extent to which parties actually bear the costs which the particular tests impose on them." Guido Calabresi \& Jon Hirschoff, Towards a Test for Strict Liability in Torts, 81 YALE L. J. 1055, 1059, n. 17 (1972).

${ }^{5}$ As Calabresi puts it: "Our society is not committed to preserving life at any cost. In its broadest sense, this rather unpleasant notion should be obvious." Guido Calabresi, The Decision for Accidents: An Approach to Non-Fault Allocation of Costs, 78 HARV. L. REV. 713, 716 (1965).
}

${ }^{6}$ See Alan Hunt, The Theory of Critical Legal Studies, 6 OXF. J. LEG. STUd. 1 (1986). 


\section{B. Conceptualizing Distribution in Environmental Policy}

In their much-cited compilation of economists writing on the distributional effects of environmental policies, Serret and Johnstone of the OECD Environment Directorate identify distribution as pertaining to two domains: The distribution of environmental effects and distribution of economic effects-understood as the distribution of wealth. Intuitively, the distribution of economic and environmental interests seems to be the core concern of environmental policy. These two domains could be in conflict: Progressive environmental effects for some agents could have regressive economic effects for other agents, ${ }^{7}$ and progressive economic effects for some agents could have regressive environmental effects for other agents. ${ }^{8}$ In some cases, progressive environmental effects can be compatible with progressive economic effects, ${ }^{9}$ but this cannot be assumed for all agents or all situations. The absence of environmental regulation may be economically beneficial for some agents over others. Counterintuitively, stringent environmental regulation may be economically beneficial for some agents. This is true not only for non-uniform distribution of wealth among producer groups and firms, but also between producers, consumers, ${ }^{10}$ environmentalists-as well as individuals and communities that are not easily categorized into such functional attributes. An agent may find herself in one of the situations provided in the table below. The focus of policymakers may lie in finding out ways to balance these conflicts or render them compatible.

\footnotetext{
${ }^{7}$ Take for instance the resistance by the agricultural sector in countries such as Ireland to environmental reform higher environmental standards would adversely affect the economic benefits of some farmers. GEORGE TAYLOR, CONSERVING THE EMERALD TIGER: THE POLITICS OF ENVIRONMENTAL REGULATION IN IRELAND 9-33 (Arlen House 2001).

${ }^{8}$ The paradigmatic example is a dam that brings several general economic benefits but affects the ecological relationship of some communities with their surroundings. See, for instance, the controversy around the Sardar Sarovar Dam and the Narmada River Valley Project in India. ARUNDHATI RoY, The Greater Common Good, in THE ALGEBRA OF INFINITE JUSTICE: COLLECTED ESSAYS 43-142 (2002). Despite the dialogic space opened by courts when claims are made using the language of rights, the human rights regime can do very little to "address the problems and plights of people affected by large dams and major public projects." Upendra Baxi, What Happens Next is Up to You: Human Rights at Risk in Dams and Development, 16 AM. U. INT'L L. REV. 1507, 1520-22 (2001).

9 States with stringent environmental standards have historically been global leaders in pollution control technologies. PETER N. GRABOSKY, Governing at a Distance: Self-Regulating Green Markets, in MARKETS, THE STATE AND THE ENVIRONMENT 197-228 (Robyn Eckersley ed. 1995). More recently, some parties have developed a comparative advantage in developing goods and services in response to climate change. One example is the Netherlands' leadership in sea walls. MCKenZIE FUNK, WINDFALL: THE BOOMING BUSINESS OF GLOBAL WARMING 215-34 (2015).

${ }^{10}$ As Maloney and McCormick put it, "the interests of environmentalists and producers may coincide against the welfare of consumers." Michael T. Maloney \& Robert E. McCormick, A Positive Theory of Environmental Quality Regulation, 25:1 J.L. \& ECON 99, 100 (1982).
} 


\begin{tabular}{|c|c|c|}
\hline \multirow{3}{*}{ 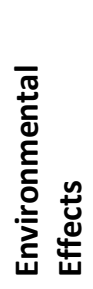 } & \multicolumn{2}{|l|}{ Economic Effects } \\
\hline & $\begin{array}{l}\text { Progressive Environmental } \\
\text { Effects + Progressive Economic } \\
\text { Effects }\end{array}$ & $\begin{array}{l}\text { Regressive Environmental Effects + } \\
\text { Progressive Economic Effects }\end{array}$ \\
\hline & $\begin{array}{l}\text { Progressive Environmental } \\
\text { Effects }+ \text { Regressive Economic } \\
\text { Effects }\end{array}$ & $\begin{array}{l}\text { Regressive Environmental Effects + } \\
\text { Regressive Economic Effects }\end{array}$ \\
\hline
\end{tabular}

If we were to probe the categories of economic effects and environmental effects a little, then other mysteries emerge. Such as what yardstick do we use to assess the nature of the economic effects of an instrument? And how do we categorize and differentiate the agents who would be affected? As indicated above, the effects on consumers would be different from the effects on producers. ${ }^{11}$ Working even within the limited yardstick of wealth distribution, Serret and Johnstone point out that it would be presumptuous to assess the impacts on all consumers on the basis of current household income. Income over the household life-cycle may lead to differential preferences: consumers with high-income expectations, such as young professionals, may apply a higher discounting rate to their current income than consumers with low-income expectations, such as temporary workers. The word preference itself has been brought into question by behavioral economics; willingness-to-pay is not an accurate reflection of actual choices. The importance of willingness-to-lose $\mathrm{e}^{12}$ as a yardstick of choice mooted by behavioral economists is reflected in the possibility of hold-out of property rights and the "plurality of incommensurable values $^{\prime 13}$ identified in environmental disputes. The picture gets a little more complex if the distributional concerns of environmental policy instruments are not restricted to the assessment of individual preferences.

A concentration of preferences shifts the concentration from the state of affairs in which individual decisions are made. Measuring environmental benefits brought about by a policy would only be possible if there is consensus on the state of affairs against which such benefits can be assessed. Thus, for the sake of devising a policy instrument, it is preferable to consider a distribution-neutral state of affairs. The assessment of the economic effects of a policy is not as distributionally neutral, as the economic effects would vary depending on how the population being considered was situated prior to the policy that comes into being. The economic effects-or the redistribution of wealth-would not capture any subjective

\footnotetext{
${ }^{11}$ Don Fullerton, Six Distributional Effects of Environmental Policy, 31:6 RISK ANALYSIS 923 (2011).

12 Other than loss aversion, willingness-to-accept is the other standard influenced by behavioral economics. Elizabeth Hoffman \& Matthew Spitzer, Willingness to Pay vs. Willingness to Accept: Legal and Economic Implications, 71 WASH. U. L.Q. 59 (1993).

13 J. Martinez-Alier, Review of The Distributional Effects of Environmental Policy, 63 ECological ECon. 243, 247 (2007).
} 
benefits and burdens borne by individuals or collectives, however. ${ }^{14}$ The distribution of benefits and burdens could instead be a better heuristic. This does not, however, address the question of benefits and burdens for whom. There is an assumption of the distribution of membership of agents who are considered for the purpose of assessment. This distributional choice is made with regard to the bounded community of people who are considered across time and space. This makes a climate policy particularly complex for the distribution of membership, as the effects cut across not only political boundaries, but also generations. The choice of distribution of membership also pertains to nonhuman elements of the environment. To include the hen harrier as against the seagull for the purpose of environmental protection is a distributive choice. Finally, any policy choice includes a mechanism for the satisfaction of such policy; this is essentially a choice regarding the distribution of responsibility in carrying it out. The absence of an explicit choice regarding the distribution of responsibility legitimizes the status quo in putting the policy into effect. This requires agents-however they are placed-to bear the burden of implementation and enforcement through self-regulation or informal negotiations, under the shadow of the institutional framework within they are situated. Either option-whether a policy mechanism spells out and/or facilitates the division of responsibility or chooses not to-is a distributive choice.

Litigation may be one way out of combating distributional iniquities using tools found in both private and public law. Both administrative and constitutional law may provide separate remedies depending on the jurisdiction in question. Within public law, courts perform a regulatory function-either by filling gaps within policies, shaping administrative action, or paying attention to interests or variables that were not given adequate weight in the policymaking process. The differential attention to variables while formulating an environmental instrument may be considered an inequitable decision that constitutes a form of distributional injustice. ${ }^{15}$ With regard to environmental policy-making generally, certain interests are given more weight than others, while others are compromised. This is especially true when a new policy gives visibility ${ }^{16}$ to some risks, responds to some more than others, and creates new risks as well in the process. ${ }^{17}$ With respect to climate change, this may amount to the differences in the vulnerability of populations across time and space.

\footnotetext{
${ }^{14}$ Sunstein explains that regulators may indeed lack relevant tools for converting benefits into money. There might be policies, however, where monetization may not be the appropriate basis for policy owing to the non-quantifiable nature of burdens and benefits. CASS SUNSTEIN, VALUING LIFE: HUMANIZING THE REGULATORY STATE 68 (2014).

${ }^{15}$ Bullard's pioneering work highlighted the invisibility of race and class in environmental policy choices, and how they may be overcome. Robert Bullard, Dumping In DixIE: RaCE, Class AND ENVIRONMENTAL Quality (1990).

${ }^{16}$ The framing of the problem necessarily affects the framing of solutions, and those solutions can take a variety of forms. This is also why public participation becomes important at both the policy-making stage as well as improving the accessibility of courts.

17 Sunstein refers to these risks as the "ancillary risks" that "regulated risks" create. CASS SUNSTEIN, RISK AND REASON: SAFETY, LAW AND THE ENVIRONMENT 134 (2002).
} 
In recent years, the implementation of international instruments such as the Aarhus Convention have built in mechanisms of compelling legal authorities to provide access to information and put in place structures to ensure meaningful ${ }^{18}$ public participation in formulating and reviewing regulation.

Given that environmental law touches on human welfare in several ways, it would be difficult to limit the scope of the justice considerations of an environmental policy choice. Scholars are divided on the scope of the phrase "environmental justice." Timothy Luke argues that the nonhuman is an integral part of environmental justice, ${ }^{19}$ while Andrew Dobson is clear that environmental justice is concerned about the distribution of goods and public bads-such as risks among humans. ${ }^{20}$ Dobson also argues that the conceptual mingling of development and justice-such as how the reduction of poverty would reduce the exploitation of the environment-is an empirical question. Agyeman and Evans distinguish between environmental justice at an "activist or local" level that is "a vocabulary for political opportunity, mobilization and action" and "policy principle" at a "governmental level" where the meaning essentially is that "no public action will disproportionately disadvantage any particular social group." ${ }^{21}$ This sharp distinction is difficult to maintain in environmental law where the local via public participation is an essential part of environmental policy. Further, given that law inevitably generalizes, not all forms of activist justice are given legal support unless they are brought within the language of proportionality or fairness. ${ }^{22}$ The way the phrase environmental justice is understood seems to be a combination of these two factors: (i) Non-discrimination among different community interests in relation to environmental benefits, and (ii) procedural rights to ensure participation. It is in this way that discourses on justice has been generalized into environmental law. This process seems inevitable as several competing and possibly incommensurable interests are reduced to the generalized operation of law. With respect to the European legal order, the translation of equality into non-discrimination is further mediated by the proportionality principle-some forms of discrimination may be justified as

\footnotetext{
18 The understanding of meaningful participation or involvement differs across jurisdictions. See Carine Nadal, Pursuing Substantive Environmental Justice: The Aarhus Convention as a 'Pillar' of Empowerment, 10 ENV'T L. REV. 28, 36-44 (2008).

19 Timothy Luke, CAPitalism, Democracy And ECology: Departing from Marx (1999).

20 ANDREW DOBSON, Justice AND the ENVIRONMENT: CONCEPTIONS OF ENVIRONMENTAL SUSTAINABILITY AND DiMENSIONS OF SOCIAL JUSTICE (1998).

21 Julian Agyeman \& Bon Evans, Just Sustainability: The emerging discourse of environmental justice in Britain?, 170:2 GeographicAL J. 155, 156 (2004).

${ }^{22}$ A similar process is at work in the inability of theories of justice in capt uring injustice claims. As Yack observes, "the raw and wildly diverse mix of complaints inspired by our sense of injustice gives us access to parts of that complex world that our familiar theories of justice... rarely enter." Bernard Yack, Putting Injustice First: An Alternative Approach to Liberal Pluralism, 66 SOC. RESEARCH 1117 (1999). The idea of the inability of a "normal model of justice" to capture senses of injustice may be attributed to Shklar. JUDITH SHKLAR, THE FACES OF INJUSTICE (1990).
} 
long as there are no disproportionate burdens. ${ }^{23}$ The proportionality qualifier makes environmental justice essentially a question of distribution. Interestingly, the examination of distributed burdens and benefits that people enjoy prior to specific policies, and the distributional impacts of policy choices provide greater scope for the consideration of how people are situated than the expression of environmental justice concerns. Take for instance the contrary claims about the relevance of environmental justice in the legal framework of the EU. Vanheusden observes that "the fact that the term environmental justice is not wellknown in Europe does not necessarily mean that European environmental policy is unjust."24 Antypas et. al. observed that there is a "regulatory vacuum" in the EU in addressing environmental justice concerns. ${ }^{25}$ How do these commentators arrive at diametrically opposite conclusions, and how can they be reconciled? This may be explained by the distributive choices of the authors. Vanheusden, on the one hand, relies on a study of difference in the environmental effects on people-according to criteria such as nationality and family situation-residing in three industrial sites in Belgium, and arrives at the conclusion that "no specific group of persons is exposed more to environmental pollution" given relatively less distributional differences in the members of the population sample studied. ${ }^{26}$ This leads him to conclude that there is fair treatment and therefore no environmental injustice. Antypas et. al., on the other hand, looks at the "distribution of harms/risks" to communities across the EU and find that Romani communities in Europe suffer environmental injustice as they have greater exposure to "hazardous waste and chemicals, vulnerability to floods, limitations on access to potable water, and waste management practices." ${ }^{27}$ Thus, if the idea of fairness or justice in the two studies is analyzed in the context of distribution, then it would be clear that the differences in the way distribution of benefits and burdens is understood, and the distribution of membership considered leads to the different conclusions arrived at.

In addition to the translation of justice concerns into environmental law, what may be gleaned from the above is the dual importance of equality and participation. These two

23 Justified differential treatment is legal provided such treatment "is based on an objective and reasonable criterion, that is, if the difference relates to a legally permitted aim pursued by the legislation in question, and it is proportionate to the aim pursued by the treatment." Case C-127/07, Sociéte Arcelor Atlantique et Lorraine v. Premier Ministre, para. 47 (2008), http://curia.europa.eu/.

${ }^{24}$ Bernard Vanheusden, The Relevance of Environmental Justice for the Legal Framework in the European Union, 7 J. EUR. ENV'T \& PLAN. L. 163, 165 (2010).

${ }^{25}$ Alexios Antypas, Claude Cahn, Richard Filcak \& Tamara Steger, Linking Environmental Protection, Health, and Human Rights in the European Union: An Argument in Favour of Environmental Justice Policy, 20 ENV'T L. \& MGMT. 8,21 (2008).

${ }^{26}$ For instance, Vanheusden observes "there are for example not more immigrants than on average in Belgium" as he considers origin and nationality to be a criterion for a collective exposed to pollution. Vanheusden, supra note 24 , at 169 .

${ }^{27}$ Antypas, supra note 25 , at $10-11$. 
factors allow for another category in the typology of distribution: The distribution of capabilities where some individuals or communities may be more capable than others in articulating and securing their interests. Take for instance the procedural requirement of public participation found in particular instruments such as the EU Environmental Impact Assessment Directive, or more generally in the EU Public Participation Directive. Should the implementation of the requirement address the issue of differential costs of approaching judicial bodies to contest policy choices and environment-related harms not captured in existing policies, then this would be an example of addressing the distributional issue of differences in capabilities of using law to address environmental concerns.

\section{Focusing on Distributive Choices in Regulatory Decisions}

It has been suggested above that distributional concerns are at the heart of environmental law. The typology of distribution provided above-distribution of benefits and burdens, distribution of membership, distribution of responsibility, distribution of capabilities-may be helpful in thinking through regulatory choices. At the same time, it may appear that regulatory decision-making may become extremely difficult if all such concerns have to be accounted for. On the contrary, it may be suggested that distribution may shift the focus onto practical decision-making. In regulatory decision-making, the choice of instruments involves not only a substantial amount of discretion in conducting qualitative cost-benefit analyses, but also identifying the conditions under which such analyses can take place. ${ }^{28}$ Given the inevitability of categorical judgements and generalizations with respect to regulatory choices, some interests would win out over others. The "middle-theorizing" of distribution makes incommensurable notions of fairness and hypothetical models of efficiency compatible. ${ }^{29}$ The decision to either adopt or reject a particular policy instrument or choose one policy instrument over another would inevitably entail a choice of a distributional state of affairs. To distinguish between policies that redistribute-and, therefore, conventionally within legislative remit-or those that do not is itself a political choice about forms of redistribution that are in the public interest. From a libertarian perspective, wealth transfers from private agents to the state would be seen as

\footnotetext{
${ }^{28}$ SUNSTEIN, supra note 14 , at 66.

${ }^{29}$ Hockett shows that utilitarianism is prescriptively sterile as people are not "passive utility factories." Rawlsian justice theory cannot provide pointers for recognizing or designing societies based on prioritarian views. Further institutional micro-changes as favored by "normative law \& economics" suffer from an endogeneity problem as it seeks to put into effect "isolated micro-changes wrought relative to prior backdrop of entitlements." In contrast, a nuanced view of distribution would allow for a normative prescriptive view of regulation. Robert C. Hockett, Putting Distribution First, 18 THEORETICAL INQUIRIES IN L. 159, 208-11 (2017). This is in keeping with the Calabresian attempt at doing away with distributional agnosticism; this is evident in the concentration on factors such as loss-spreading, identifying the "least-cost avoider" as a way of thinking about entitlements, and assessing regulatory options. For a review of the Calabresian view, see James R. Hackney Jr., Guido Calabresi and the Construction of American Legal Theory, 77:2 L. \& CONTEMP. PROBS. 45 (2014). Calabresi and Hirschoff further clarify that when different liability rules "have . . . different distributional effects ... distributional differences may well determine the approach taken." Calabresi \& Hirschoff, supra note 4, at 1077.
} 
redistribution, while federal lenses would look at wealth transfers between different levels of government as redistribution. If we stepped out of the requirement to view distributional choices as instrumental to decisions about division of powers and separation of powers, then regulation itself could be viewed as a choice about the identification and shaping of distributional concerns. In this light, judicial review of policy instruments could be viewed as regulatory shaping: Rescuing impacts from the interests that shape regulatory choices, requiring consideration of interests that have been neglected, and giving weight to changes in the state of affairs brought about by regulation. Bringing the focus on distributional concerns allows regulation to be reasoned interpretation, iterative, and highlights the regulatory role of judicial bodies. ${ }^{30} \mathrm{It}$ provides for a mechanism to engage in detailed ex-ante inquiry in choosing policy instruments, allowing for an integration of economic, environmental and social concerns in impact analysis, planning decisions and other such assessments. ${ }^{31}$ This is not only to take stock of the state of affairs in which regulation takes place, but also the potential of policy instruments to reconstitute the way different agents are positioned with respect to such concerns. ${ }^{32}$ Further, the concentration on distribution precludes the displacement of post-hoc litigation to ensure that the value of equality is not given short-shrift by providing a mechanism for the articulation and addressing of neglected or unprivileged interests. ${ }^{33}$

\section{Distributive Choices in EU Climate Policy and the EU ETS}

Categorizing the European Union Emissions Trading Scheme (EU ETS) as a market instrument has practical benefits. It does not need to be billed as a tax in its extraterritorial application, ${ }^{34}$ and it did not need to be classified as a fiscal mechanism, which avoided a stricter legislative approval procedure. ${ }^{35}$ It is not a strictly market mechanism, however, once we consider the

${ }^{30}$ See, for instance, Hari M. Osofsky \& Jacqueline Peel, Litigation's Regulatory Pathways and the Administrative State: Lessons from U.S. and Australian Climate Change Governance, 25 GEO. ENV'T L. REV. 2017 (2013).

${ }^{31}$ Gordon Walker, Environmental Justice, Impact Assessment and the Politics of Knowledge: The implications of assessing the social distribution of environmental outcomes, 30 ENV'T IMPACT ASSESSMENT REV. 312, 313 (2010).

${ }^{32}$ The inevitability and normative potential of regulation to organize relations and achieve objectives, an either-or preference for centralized regulation or deregulation is misplaced. Richard B. Stewart, Reconstitutive Law, 46 MD. L. REV. 46 (1986).

${ }^{33}$ As Walker puts it, " . . giving attention to questions of distribution may serve to sustain or generate conflict around environmental decisions-because hidden patterns of disproportionate impact on particular groups may be revealed and become politicised; because evidence of distributions is not uncontroversial either in the methods or in the processes of its production." Walker, supra note 31, at 318.

${ }^{34}$ A central argument for why the extension of the EU ETS to non-EU aviation companies was compatible with international aviation law was because the EU ETS is a market mechanism and not a tax. Case C-366/10, Air Transp. Ass'n of Am. v. Sec'y of State for Energy \& Climate Change (2011), http://curia.europa.eu/.

35 The EU ETS was approved under the Treaty on the Functioning European Union art. 192(1) [hereinafter TFEU] which provides measures that can be adopted by the Council and Parliament by following an ordinary legislative procedure involving a qualified majority vote in the Council. The European Commission Proposal for a carbon tax 
high penalties for non-compliance, ${ }^{36}$ the regulatory investment in identifying and facilitating the involvement of parties through carbon accounting inventories, and detailed Monitoring, Reporting and Verification (MRV) procedures. It is suggested that the EU ETS is better understood by examining the distributive choices embedded in the instrument.

There is a distribution of responsibility on Member States to adopt differential reduction targets through the Effort Sharing Decision. ${ }^{37}$ The target adopted by the EU is pursuant to international commitments, which in turn are distributive choices: Some states in the world have assumed greater responsibility than others; and the determination of such responsibility involves the assessment of risks to future generations, and hypothetical distribution of wealth over time via discounting rates. After Member States in the EU have been distributed responsibility, there is a further crucial distribution of responsibility to firms included in the EU ETS to invest in the purchase of allowances in the current phase and adhere to the scheme or pay high penalties. The Directive was the product of intense negotiations by industrial actors, as is reflected by the difference in the original Commission Green Paper on the EU ETS and the final directive that was released. ${ }^{38}$ The differences reveal political contests with regard to the attribution of abatement responsibility through the inclusion of some sectors, as well with regard to the nature of allocation: The Commission's attempts at introducing auctioning of allowances received heavy opposition from industrial actors, eventually giving way to freely allocated allowances. Analyzing the political economy of EU climate policy, Meckling concludes that "the rise of carbon trading can partially be understood as a strategy of big emitters to prevent the introduction of carbon taxes." ${ }^{\prime \prime 9}$ With respect to aviation, extraterritorial aviation companies are also distributed responsibility. Consumers are not distributed any direct responsibility under the scheme, but there is a distribution of burdens, ${ }^{40}$ as producers that are part of the EU ETS may pass-through costs

\footnotetext{
was shot down under TFEU art. 192(2) which requires the Council to follow a special legislative procedure involving a unanimous vote when it seeks to adopt measures that are "primarily of a fiscal nature."

${ }^{36}$ The operation of strict liability is evident from a couple of cases where the Court of Justice of the European Union effectively ruled that in the absence of force majeure, there is no room for firms to negotiate either the penalty or the reparations requirement. C-203/12, Billerud Karlsborg Aktiebolag v. Naturvårdsverket (2012), http://curia.europa.eu/; Case C-580/14, Sandra Bitter v. Bundesrepublik Deutschland (2015), http://curia.europa.eu/.

${ }^{37}$ Decision No. 406/2009, OJ (L 140) (EC).

38 Peter Markussen \& Gert Tinggard Svendsen, Industrial Lobbying and the Political Economy of GHG Trade in the European Union, 33 ENERGY POL'Y 245-55 (2005).

39 Jonas Meckling, Carbon Coalitions: Business, Climate Politics And the Rise Of Emissions Trading 48 (2011).

${ }^{40}$ Caney clarifies that the primary distinction between distribution of responsibilities and distribution of burdens is that the former deals with the assignment of duties or responsibilities to prevent climate change, which is in effect the assignment of liability "of those who have failed to comply with theirs [responsibilities]." The latter deals with the imposition of burdens on third-parties without responsibilities by those who have been assigned such responsibilities. Such burdens may be justified given the "priority of climate change;" it amounts to "appeasing reluctant emitters [or responsibility bearers] and acceding to their demands to bear less costs than they ought to."
} 
to consumers. ${ }^{41}$ This is in stark contrast to the federal arrangement in China for instance, where costs incurred by installations are prohibited from being passed through to consumers. ${ }^{42}$ Further, it has been shown that some sectors-primarily the electricity sector-have been successful in passing through costs to consumers. ${ }^{43}$

The distribution of membership is a bit more difficult to assess. It may seem that the parties included in the EU ETS could double-up as the members for the purpose of assessing membership. This is true for the purpose of responsibility. Membership for the distribution of burdens and benefits, however, is different. Should the EU ETS be considered successful in reducing carbon emissions, then this is a global benefit with regard to environmental effect. This benefit may be distributed differentially over time-intergenerationally-and space-beyond the territorial confines of the state. With respect to economic effects, the EU ETS provides a regressive economic effect for some firms-as least in the short to medium term-included within the scheme. This issue animates concerns regarding the possible infringement of the EU ETS on the freedom to carry out economic activities, and the possibility of investment leakage, where firms might choose to relocate to jurisdictions where the EUETS does not hold sway. It could, however, be economically beneficial for some firms as well through the enjoyment of scarcity rents. The allocation of free allowances in Phase I could well have resulted in economic benefits for some sectors-though this benefit may have been redistributed to invest in energy efficiency technologies. Further, participation in the EU ETS may have conferred an opportunity benefit by avoiding the impending inclusion in a costlier climate instrument.

Picking up on carbon accounting and MRV briefly mentioned above, assessing the distribution of benefits does not need to be restricted to environmental benefits or economic benefits enjoyed by some firms or sectors over others. Administrative cost-saving in accounting for emissions reduction is a notable benefit that the EU ETS affords. Carbon accounting in the EU-as is manifested in carbon inventories for monitoring and reportingis based on the production of goods and energy in Member States ${ }^{44}$ above a certain

Simon Caney, Climate Change and Non-Ideal Theory: Six ways of Responding to Noncompliance, in CLIMATE JUSTICE IN A NON-IDEAL WORLD 25-28 (Clare Heyward \& Dominic Roser eds., 2016).

${ }^{41}$ The European Court of Justice observed that the pass-through of costs by producers included in the EU ETS to consumers is not prohibited, but, at the same time, not essential for reducing emissions. Cases C-566/11, C-567/11, C-580/11, C-591/11, C-620/11 and C-640/11, Iberdrola v. Administración del Estado (2013), http://curia.europa.eu/.

${ }^{42}$ See ZhongXiang Zhang, Carbon Emissions Trading in China: The Evolution from Pilots to a Nationwide Scheme, CCEP Working Paper 1503 (2015).

${ }^{43}$ T. Laing, M. Sato, M. Grubb \& C. Comberti, The Effects and Side-effects of the EU Emissions Trading Scheme, 5 WIREs ClimATE CHANGE 509 (2014).

${ }^{44}$ Glen P. Peters \& Edgar G. Hertwich, Post-Kyoto Greenhouse Gas Inventories: Production Versus Consumption, 86 CLIMATIC CHANGE 51 (2008). 
threshold: These are the direct sources of emissions accounted for. The Community Independent Transaction Log (CITL) database-the go-to point for transparency regarding the units covered, monitored, and allowances transacted-contains only information on activities of installations above the threshold mentioned in the EU ETS Directive. This producer-based territorial model of carbon accounting allows for the distribution of climate responsibility to Member States and some installations as discussed above. It more importantly tries to effectively monitor emissions while arresting the possibility of double counting of emissions. ${ }^{45}$ Such distributional choices may also be viewed as choices regarding the distribution of capabilities: Small installations that suffer high costs of MRV and may find participation in a carbon market difficult are excluded from the ambit of the EU ETS. In a couple of cases filed by Arcelor Atlantique, the General Court and the Court of Justice of the European Union found that the EU ETS satisfied the proportionality test in relation to Arcelor's right to property and the right to conduct economic activity as it did not-among other considerations-result in "substantial negative economic consequences." ${ }^{46}$ The Court accepted that there was a difference in treatment of those parties included in the EU ETS, but such different treatment did not amount to unequal treatment: It was not "unequal treatment of comparable situations," but rather "equal treatment of dissimilar situations." ${ }^{\text {"4 }}$ This logic may be difficult to apply to smaller installations that are not as capable of adaptation to the regulatory complex of the EU ETS, or to people in case of a hypothetical emissions trading scheme for households, ${ }^{48}$ where the consequences may not be solely economic in nature, and capabilities may not be amenable to commensurability. ${ }^{49}$

\footnotetext{
${ }^{45}$ The problem with Double Counting is if a single abatement action is counted more than once. This would be a problem as there would potentially be an overestimation of the amount of emissions mitigated. If the primary proxy for the effectiveness of a climate policy is the satisfaction of climate targets, then the targets would be met sooner with an accounting inflation. In other words, a quantity mechanism proxied through the satisfaction of a climate target would not correspond with actual abatement. Steven Sorrell, Who Owns the Carbon? Interactions Between the EU Emissions Trading Scheme and the UK Renewables Obligation and Energy Efficiency Commitment, 14 ENERGY \& ENV'T 677, 692-94 (2003).

${ }^{46}$ Case T-16/04, Arcelor v. European Parliament \& Council of the European Union, 2010 E.C.R. II-211, para. 168 (2010).

${ }^{47} / d$. at para. 167.

${ }^{48} \mathrm{~A}$ carbon trading scheme for households was considered by the Environmental Audit Committee of the House of Commons in the United Kingdom but was found non-implementable. Environmental Audit Committee, HC, Personal Carbon Trading: Government Response to the Committee's Fifth Report of Session 2007-2008 (May 26, 2008) (UK).

${ }^{49}$ It would be incorrect to characterize the EU ETS as a policy mechanism mediated solely by market interests, owing to the heavy regulatory oversight and liability to pay a fine for non-compliance, as discussed in this Article. These features in combination with sophisticated market instruments create the climate policy complex in the EU that makes different interests commensurable. This is why the EU ETS is uniquely placed in the distribution of responsibility to States and firms, and perhaps not to other entities where human and non-human interests would have to be valued. For a discussion, see Steffen Dalsgaard, Carbon Value Between Equivalence and Differentiation, 5 ENV'T \& SOC'Y 86 (2014).
} 
Notwithstanding the potential of distribution of capabilities as an analytical category that might shape policy choices, it is unclear whether it is given as much importance as the distribution of benefits, or even explicitly feature in formal proportionality analyses of EU climate policy. ${ }^{50}$ Though the Arcelor cases point to the possibility of unfavorable consequences, they endorse the importance of the administrative complexity of the EU ETS that legitimizes the burdens that are imposed on some agents over others. ${ }^{51}$ In the Iberdrola judgment, the Court points to the primary objective of the EU ETS to reduce emissions substantially and does not pay much heed to sub-objectives; ${ }^{52}$ it can only be surmised that a pressing need for achieving progressive environmental effects in keeping with the distribution of responsibility under the Kyoto Protocol and the EU takes precedence over other distributional concerns. Having said that, the ability of Member States and some private parties to influence the distribution of benefits and burdens may well shape the adoption of some attributes of climate policy over others-this could distort the achievement of progressive environmental effects. ${ }^{53}$

\section{E. Conclusion}

This Article highlights the centrality of distributional concerns in choosing between different environmental policy instruments and thinking through environmental regulation in general. It has been suggested that any policy instrument needs to be mindful of (i) the context in

\footnotetext{
${ }^{50}$ This does not, however, discount the meta-principle of proportionality in thinking through the institutional basis and individual policy instruments in the EU policy framework. Cendra de Larragan argues that this meta-principle is helpful in assessing the characteristics of any policy instrument with respect to (i) the relationship between means and ends; (ii) the distribution of benefits and burdens; and (iii) the participation of those affected by the regulation in question. Javier Cendra de larragan, Distributional Choices in EU Climate Change law and Policy: Towards a PRINCIPLED APPROACH? 11 (2011).

51 The "objective and reasonable criterion" to gauge the "appropriateness of Community legislative action" in this case was "administrative feasibility" and "administrative complexity" of the EU ETS that is "novel and complex": The Court felt that based on administrative concerns, for the purpose of the implementation of the EU ETS, it is necessary "attain the critical mass of participants necessary for the scheme to be set up" in a step-by-step manner. Société Arcelor Atlantique et Lorraine and Others, supra note 23 at para. 60.

52 Iberdrola, supra note 41 at para. 79. This can be gleaned from the fact that unlike Advocate General Kokott's identification of energy efficiency as an objective integral to the EU ETS, the Court considers all objectives other than emissions reduction as sub-objectives. For a discussion, see Daniel Perez Rodriguez, Absorbing EU ETS Windfall Profits and the Principle of Free Allowances: Iberdrola and Others, 51 CoMmon MKT L. REV. 679, 690-693 (2014).

${ }^{53}$ Given the ability of some EU institutions, Member States, and private parties to shape the distribution of responsibility, burdens and benefits, and accordingly avoid a carbon tax, it is highly unlikely that a tax would be given due consideration from the point of progressive environmental effects. Even if we were to accept the nonviability of a tax, there could be changes made to the EU ETS itself to ensure achievement of progressive environmental effects. It has been argued that setting a price floor may well enhance the environmental integrity of the EU ETS to ensure that the price set by the market does not compromise the effectiveness of the binding emissions cap. Frédéric Branger, Oskar Lecuyer, Philippe Quirion, The European Union Emissions Trading Scheme: Should we throw the flagship out with the bathwater?, 6 WIRES CLIMATE CHANGE 9, 12 (2015).
} 
which different interests are negotiated and preferences are situated, and (ii) the potential to bring about changes with respect to diverse interests and values. Such interests, preferences, and values can be made commensurable using the language of distribution. Within distributional analyses, the conventional method is to assess preferences and balance environmental and economic effects. This exercise is valuable in assessing permutations of progressive and regressive environmental and economic effects. It does not, however, address questions regarding whether and how preferences can be assessed, the possibility of non-economic effects, and for whom. From a prescriptive point of view, such concerns do not also address who is to shoulder what burdens. It is for this reason a typology of distributional concerns has been suggested for regulatory decisions: Distribution of benefits and burdens, distribution of responsibility, distribution of membership, and distribution of capabilities. These analytical categories were applied to EU climate policy to describe distributional concerns in the EU ETS, and the role of the proportionality principle in mediating justified unequal treatment and burdens was noted. It has also been argued that distributional concerns and effects cannot always be anticipated or addresses, for which litigation and meaningful public participation become important components of environmental policy-making. 
